\title{
Dovitinib in patients with gastrointestinal stromal tumour refractory and/or intolerant to imatinib
}

Heikki Joensuu *,1, Jean-Yves Blay², Alessandro Comandone ${ }^{3}$, Javier Martin-Broto ${ }^{4}$, Elena Fumagalli ${ }^{5}$, Giovanni Grignani ${ }^{6}$, Xavier Garcia Del Muro ${ }^{7}$, Antoine Adenis ${ }^{8}$, Claudia Valverde ${ }^{9}$, Antonio Lopez Pousa ${ }^{10}$, Olivier Bouché ${ }^{11}$, Antoine Italiano ${ }^{12}$, Sebastian Bauer ${ }^{13}$, Carlo Barone ${ }^{14}$, Claudia Weiss ${ }^{15}$, Stefania Crippa ${ }^{16}$, Maura Camozzi ${ }^{16}$, Ramon Castellana ${ }^{17}$ and Axel Le Cesne ${ }^{18}$

${ }^{1}$ Department of Oncology, Helsinki University Hospital and University of Helsinki, Haartmaninkatu 4, Helsinki, Finland; ${ }^{2}$ University Claude Bernard Lyon I, Centre Leon Berard, Lyon, France; ${ }^{3}$ Gradenigo Hospital, Torino, Italy; ${ }^{4}$ Hospital Universitario Virgen del Rocio, Sevilla, Spain; ${ }^{5}$ Fondazione IRCCS Istituto Nazionale dei Tumori, Milan, Italy; ${ }^{6}$ Sarcoma Unit, Candiolo Cancer Institute-FPO, IRCCS, Candiolo, Italy; Institut Catala d'Oncologia, IDIBELL, Barcelona, Spain; ${ }^{8}$ Centre Oscar Lambret, Lille, France; ${ }^{9}$ Vall d'Hebron University Hospital, Barcelona, Spain; ${ }^{10}$ Hospital de La Santa Creu i Sant Pau, Barcelona, Spain; ${ }^{11}$ University Hospital Robert Debre, Reims, France; ${ }^{12}$ Institut Bergonie, Comprehensive Cancer Centre, Bordeaux, France; ${ }^{13}$ Sarcoma Center, West German Cancer Center, University of DuisburgEssen, Essen, Germany; ${ }^{14}$ University Hospital A. Gemelli, Universitá Cattolica, Rome, Italy; ${ }^{15}$ Novartis Pharma GmbH, Nuernberg, Germany; ${ }^{16}$ Novartis Farma, Origgio, Italy; ${ }^{17}$ Novartis Farmaceutica SA, Barcelona, Spain and ${ }^{18}$ Gustave Roussy, Villejuif, France

Background: This multicentre phase II trial (DOVIGIST) evaluated the antitumour activity of dovitinib as second-line treatment of patients with gastrointestinal stromal tumour (GIST) refractory to imatinib or who do not tolerate imatinib.

Methods: Patients received oral dovitinib $500 \mathrm{mg}^{\text {day }}{ }^{-1}, 5$ days on/2 days off, until GIST progression or unacceptable toxicity, with an objective to evaluate efficacy, assessed as the disease control rate (DCR) at 12 weeks. Tumour assessment and response to dovitinib therapy were evaluated by Response Evaluation Criteria In Solid Tumours (RECIST v1.1) and the Choi criteria. Secondary objectives included assessment of progression-free survival (PFS), safety and tolerability, and DCR at the end of treatment.

Results: Thirty-eight of the 39 patients enrolled had histologically confirmed GIST. The DCR at 12 weeks was 52.6\% (90\% confidence interval (CI), 38.2-66.7\%) meeting the preset efficacy criterion for the primary end point. The objective response rate (complete response + partial response) was $2.6 \%(1$ of $38 ; 90 \% \mathrm{Cl}, 0.1-11.9 \%)$, and $5.3 \%(n=2 ; 90 \% \mathrm{Cl}, 0.9-15.7 \%)$ at the end of the study. The median PFS was 4.6 months ( $90 \% \mathrm{Cl}, 2.8-7.4$ months). Dose interruption was required in 26 patients (66.7\%), of which 18 (69.2\%) were due to adverse events. The most frequently observed grade 3 adverse events included hypertension $(n=7)$, fatigue $(n=5)$, vomiting $(n=4)$, hypertriglyceridaemia $(n=4)$, and $\gamma$-glutamyltransferase increase $(n=4)$.

Conclusions: Dovitinib is an active treatment for patients with GIST who are intolerant to imatinib or whose GIST progresses on imatinib.

Gastrointestinal stromal tumour (GIST) is the most frequent sarcoma of the gastrointestinal tract with an age-adjusted incidence of $\sim 6.8$ new cases per million per year (Tran et al, 2005).
However, the true incidence of GIST may be higher as incidental GISTs are relatively frequent (Agaimy et al, 2007; Muenst et al, 2011). Gastrointestinal stromal tumour is most commonly

*Correspondence: Dr H Joensuu; E-mail: heikki.joensuu@hus.fi 
found in the stomach (60-70\%), followed by the small intestine (20-30\%), colon, and rectum, and it is infrequent in the oesophagus and mesentery (Joensuu et al, 2013). The most common locations for metastases are the liver and the peritoneum (Nishida et al, 2013). Gastrointestinal stromal tumour occurs predominantly in the middle-aged and older population, with a median age at diagnosis of $\sim 60$ years (Miettinen and Lasota, 2006). Developmentally, GIST cells likely arise from pluripotent precursor mesenchymal cells that normally differentiate into the interstitial cells of Cajal and play a key role in the regulation of gut motility. Activating mutations in the KIT gene are found in 70 to $80 \%$ of primary GISTs, and mutations in the platelet-derived growth factor alpha (PDGFRA) are present in further 10 to $15 \%$ of the tumours. These mutations are considered to be early and driving oncogenic events in most GISTs (Corless et al, 2011).

Imatinib mesylate is a selective inhibitor of KIT, PDGFR $\alpha / \beta$ and BCR-ABL kinases, and was the first Food and Drug Administration-approved tyrosine kinase inhibitor (TKI) for the treatment of GIST. Imatinib is now the standard first-line treatment for advanced GIST. At present, several other TKIs are either approved or under investigation for the treatment of imatinib-resistant GIST (Bauer and Joensuu, 2015). The responsiveness of GIST to imatinib differs with the type and location of KIT or PDGFRA mutations. Patients with GIST with KIT exon 11 mutation generally achieve a longer progression-free survival (PFS) than those with KIT exon 9 mutation (Debiec-Rychter et al, 2006). Approximately 15\% of patients with GIST progress on imatinib within the first 3 months on therapy (primary resistance) if GIST genotype is not used for patient selection (Gramza et al, 2009), and further 40 to $50 \%$ develop resistance within 2 years of therapy initiation (secondary resistance) (Van Glabbeke et al, 2005). Acquired imatinib resistance often coincides with the appearance of second KIT mutations encoding for a protein resistant to imatinib (Antonescu et al, 2005).

When GIST progresses on imatinib or when the patient does not tolerate imatinib, the standard second-line treatment is sunitinib (Yoo et al, 2013). The median PFS was 5.1 months on second-line sunitinib in a randomised trial (Demetri et al, 2006) with a tendency for better PFS in patients with KIT exon 9 mutation compared with other genotypes (Pilotte, 2015). However, patients eventually progress on sunitinib. Regorafenib was approved in 2013 for the third-line treatment of patients with GIST who no longer respond to imatinib and sunitinib based on a randomised phase 3 study (Demetri et al, 2013). However, sunitinib and regorafenib are usually less well tolerated than imatinib, and may cause hand-foot syndrome, fatigue, and hypertension that may sometimes be severe, and responses to sunitinib and regorafenib may remain short. A few TKIs have been evaluated as the third-line or later line treatment post therapy with imatinib and sunitinib including nilotinib (Cauchi et al, 2012), pazopanib (Ganjoo et al, 2014), and sorafenib (Montemurro et al, 2013) (reviewed in Bauer and Joensuu, 2015).

Dovitinib is a multikinase inhibitor of the vascular endothelial growth factor receptor-1 (VEGFR-1), VEGFR-2, VEGFR-3, fibroblast growth factor receptor-1 (FGFR-1), FGFR-2, FGFR-3, $\operatorname{PDGFR} \beta$, KIT, colony-stimulating factor 1 receptor, Fms-like tyrosine kinase 3, and PDGFR $\alpha$ (Trudel et al, 2005; Porta et al, 2015). In a phase 1 study, dovitinib administration to a patient with GIST resulted in disease control for 8 months when both imatinib and sorafenib had failed (Sarker et al, 2008). Based on the kinase inhibition spectrum and the anecdotal clinical evidence, we initiated this phase 2, multicentre, open-label, single-arm, nonrandomised study to assess the antitumour activity and safety of dovitinib in patients with GIST refractory or intolerant to imatinib in the second-line setting.

\section{MATERIALS AND METHODS}

Patients. Patients $\geqslant 18$ years of age with histologically confirmed GIST that was either unresectable and/or metastatic with documented disease progression while on therapy with imatinib were eligible. Patients with surgically removed localised GIST that recurred on adjuvant imatinib or within the first 3 months after discontinuation of adjuvant imatinib were also eligible, as well as patients with unresectable and/or metastatic GIST who were intolerant to imatinib. Patients were required to have $\geqslant 1$ measurable GIST lesion at baseline and Eastern Cooperative Oncology Group performance status $\leqslant 2$. The tumours were required to be KIT-positive in immunostaining, or when KIT-negative, to stain positively for discovered on GIST-1 (DOG-1, anoctamin); patients with a tumour histologically compatible with GIST and a mutation of KIT or PDGFRA were also eligible regardless of the result of immunostaining for KIT and DOG-1. Exclusion criteria included the use of cytotoxic drugs $\leqslant 4$ weeks before initiation on dovitinib, major surgery $\leqslant 4$ weeks before starting dovitinib, history of pulmonary embolism, or untreated deep venous thrombosis within the past 6 months. Patients with impaired cardiac function, brain metastasis, or the long QT syndrome were excluded.

The study protocol and all amendments were reviewed by the independent ethics committee or institutional review board for each participating centre. Written informed consent was obtained from the patients before study entry. The study was conducted according to the ethical principles of the Declaration of Helsinki.

Study design. The primary objective was to assess the efficacy of dovitinib in terms of the disease control rate (DCR; complete response + partial response $(\mathrm{PR})+$ stable disease $(\mathrm{SD}))$, at 12 weeks on study. The secondary objectives included assessment of PFS, time to treatment failure, the duration of response and SD, time to progression (TTP), overall response rate (ORR), overall survival (OS), DCR at the end of treatment, and safety and tolerability of dovitinib. The exploratory objectives were to evaluate tumour response using the Choi criteria and to correlate response with DCR and PFS, and to assess the associations between KIT and PDGFRA mutations and tumour response and cancer progression. This study (DOVIGIST) is an exploratory, phase 2, multicentre, open-label, single-arm, nonrandomised trial.

Study drug administration. Dovitinib was administered orally ( $500 \mathrm{mg} \mathrm{day}^{-1}, 5$ days on $/ 2$ days off), and was taken either with or without food. One treatment cycle was considered to last for 28 days. Dovitinib treatment was continued until disease progression, unacceptable toxicity, death, or discontinuation from the study treatment on patient request.

\section{Study assessments}

Efficacy and safety assessments. Tumour assessment and response to dovitinib therapy were evaluated according to the Response Evaluation Criteria In Solid Tumours (RECIST v1.1) and the Choi criteria. Tumour responses were assessed by local radiological review. All known sites of tumour lesions were investigated using computerised tomography or magnetic resonance imaging at baseline within 21 days before initiating therapy, on day 28 of the cycle 1 , then every 8 weeks until 24 weeks on study, and subsequently every 12 weeks thereafter until disease progression. Whenever disease progression was suspected, additional imaging was carried out. Physical examination, blood cell counts, blood biochemistry, and urine analysis were carried out at baseline, on day 1 and 15 of the first cycle, and then on day 1 of each cycle. 
Assessment of the primary objective. The primary objective was DCR, defined as the proportion of patients with the best overall response of $\mathrm{CR}, \mathrm{PR}$, or $\mathrm{SD}$ at week 12 on study. Best overall response was assessed by the investigators according to RECIST v1.1, and it was rederived both at 12 weeks and at the end of therapy, as $\mathrm{SD} \geqslant 6$ weeks based on investigator assessment could not be confirmed in two patients. Besides the rederived assessment, the best overall response as assessed by the investigators is also provided for comparison.

The best overall response of complete response corresponded with at least two determinations of CR, at least 4 weeks apart before progression. Partial response corresponded with at least two determinations of PR or better at least 4 weeks apart but not qualifying for CR. Stable disease is defined as at least one SD assessment $>6$ weeks after the start of treatment. The best overall response was progressive disease, when disease progressed $\leqslant 6$ weeks after the start of treatment.

Patients with a best overall response assessed as 'unknown' were not regarded as responders, but were included in the denominator for the calculation of DCR. 'Unknown' was defined according to the modified RECIST criteria, that is, cases not qualifying for confirmed CR or PR and who did not have SD after more than 6 weeks or early progression within the first 6 weeks.

Safety assessments. Safety was monitored throughout the study according to the National Cancer Institute Common Toxicity Criteria for Adverse Events version 4. The side effects were graded at the scheduled visits.

Patient follow-up. All patients were followed up for 28 days after the last dose of dovitinib for safety assessments. In addition, patients discontinuing dovitinib for reasons other than death, disease progression, lost to follow-up, or withdrawal of consent continued to have tumour assessments done every 3 months until radiological progression, start of new therapy for GIST, or until 2 years had elapsed from the study entry.

Statistical considerations. The highest DCR at week 12 that would indicate the treatment with dovitinib to be clearly ineffective $\left(p_{0}\right)$ was defined as $20 \%$, as this would be below the proportion of patients who had a clinical benefit by week 22 (month 5) after treatment with sunitinib (Demetri et al, 2006), whereas $p_{1}$ was the minimum required DCR to show effectiveness, chosen to be $45 \%$. A minimum of 29 evaluable patients were required to be enrolled to test the null hypothesis $\mathrm{H}_{0}$ that $p \leqslant p_{0}$ against the alternative hypothesis $\mathrm{H}_{1}$ that $p \geqslant p_{1}$.

Analyses of primary and secondary variables were carried out using the full analysis set. Exact confidence intervals (CIs) were computed according to Clopper-Pearson using a one-sided level of significance of $5 \%$ (two-sided $\alpha$ of $10 \%$ ).

\section{RESULTS}

Patients. A total of 39 patients were enrolled in the study between January 2012 and July 2014 from 14 centres located in Europe and were included in the safety analyses. Of these, 38 patients had histologically confirmed GIST and were included in the efficacy analyses.

The median age of the 38 patients with histologically verified GIST at the time of study entry was 60 years (range, 32-77 years). Three (7.9\%) patients progressed on adjuvant imatinib, 3 within 3 months after discontinuation of adjuvant imatinib, 27 (71.1\%) had disease progression on imatinib administered for advanced GIST, and $8(21.1 \%)$ patients were intolerant to imatinib (3 patients had both progressed on imatinib and were also intolerant to imatinib). Patient demographics and baseline characteristics are summarised
Table 1. Baseline demographics and GIST characteristics

\begin{tabular}{|c|c|}
\hline Variable & Total, $\mathbf{N}=\mathbf{3 8}$ \\
\hline Median age, years & $60.0(32-77)$ \\
\hline Male, $n(\%)$ & $22(57.9)$ \\
\hline $\begin{array}{l}\text { Race, } n(\%) \\
\text { Caucasian } \\
\text { Other }\end{array}$ & $\begin{array}{r}29(76.3) \\
9(23.7)\end{array}$ \\
\hline $\begin{array}{l}\text { ECOG performance status, } n(\%) \\
0 \\
1\end{array}$ & $\begin{array}{l}23(60.5) \\
15(39.5)\end{array}$ \\
\hline $\begin{array}{l}\text { Primary site of cancer, } n(\%) \\
\text { Oesophagus } \\
\text { Stomach } \\
\text { Small intestine } \\
\text { Rectum } \\
\text { Other }\end{array}$ & $\begin{aligned} 1 & (2.6) \\
15 & (39.5) \\
15 & (39.5) \\
2 & (5.3) \\
5 & (13.2)\end{aligned}$ \\
\hline $\begin{array}{l}\text { Tumour histology, } n \text { (\%) } \\
\text { Epithelioid } \\
\text { Spindle } \\
\text { Mixed } \\
\text { Other }\end{array}$ & $\begin{array}{r}5(13.2) \\
17(44.7) \\
11(28.9) \\
5(13.2)\end{array}$ \\
\hline $\begin{array}{l}\text { Mitotic count per } 50 \mathrm{HPFs}, n(\%) \\
\leqslant 5 / 50 \\
>5 / 50 \text { to } \leqslant 10 / 50 \\
>10 / 50 \\
\text { Not evaluable } \\
\text { Missing }\end{array}$ & $\begin{array}{r}8(21.1) \\
6(15.8) \\
10(26.3) \\
9(23.7) \\
5(13.2)\end{array}$ \\
\hline $\begin{array}{l}\text { Metastatic site, } n(\%)^{\mathbf{b}} \\
\text { Pleural effusion (malignant) } \\
\text { Lung } \\
\text { Thoracic lymph nodes } \\
\text { Spleen } \\
\text { Liver } \\
\text { Stomach } \\
\text { Peritoneum } \\
\text { Adrenal } \\
\text { Bladder } \\
\text { Bone, lumbar vertebrae } \\
\text { Other }\end{array}$ & $\begin{aligned} 1 & (2.6) \\
1 & (2.6) \\
2 & (5.3) \\
1 & (2.6) \\
26 & (68.4) \\
1 & (2.6) \\
17 & (44.7) \\
1 & (2.6) \\
2 & (5.3) \\
1 & (2.6) \\
6 & (15.8)\end{aligned}$ \\
\hline Median number of target lesions (range) & $2(1-5)$ \\
\hline $\begin{array}{l}\text { Median longest diameter of the largest target lesion, } \mathrm{cm} \\
\text { (range) }\end{array}$ & $7.0(1.3-25.0)$ \\
\hline Disease progression while on imatinib, $n(\%)$ & $33(86.8)$ \\
\hline Median time on imatinib, days (range) & 132 (19-2065) \\
\hline Intolerant to imatinib, $n(\%)^{c}$ & $8(21.1)$ \\
\hline $\begin{array}{l}\text { Gene mutation } \\
\text { KIT mutation } \\
\text { Exon } 9 \\
\text { Exon } 11 \\
\text { Exon } 17 \\
\text { Exons } 11 \text { and } 17\end{array}$ & $\begin{aligned} 5 & (13.2) \\
14 & (36.8) \\
1 & (2.6) \\
1 & (2.6)\end{aligned}$ \\
\hline $\begin{array}{l}\text { PDGFRA mutation } \\
\text { Exon } 12 \\
\text { Exon } 18 \\
\text { Exon D842V }\end{array}$ & $\begin{array}{l}1(2.6) \\
1(2.6) \\
2(5.3)\end{array}$ \\
\hline Not available & $13(34.2)$ \\
\hline $\begin{array}{l}\text { Abbreviations: ECOG = Eastern Cooperative Oncology Group; HP } \\
\text { a Patients for whom the mitotic index was not recorded as fraction } \\
{ }^{b} \text { One patient may have more than one metastatic site. }\end{array}$ & $\begin{array}{l}\text { igh power fields. } \\
0 \mathrm{HPFs} \text {. }\end{array}$ \\
\hline
\end{tabular}

in Table 1. The median time period since initial GIST diagnosis to the first dose of dovitinib was 46.3 months (range, 3.5-135 months).

Efficacy. All 38 patients completed the study; the most common primary reasons for dovitinib discontinuation were disease 
Table 2. The best overall response (rederived and by investigator assessment) as per RECIST at week 12 on study and at the end of treatment

\begin{tabular}{|c|c|c|}
\hline Time-point variable & $\begin{array}{c}N=38 \\
n(\%)\end{array}$ & $\begin{array}{l}90 \% \text { confidence } \\
\text { interval }^{\mathrm{a}}\end{array}$ \\
\hline \multicolumn{3}{|l|}{ Week 12 (rederived) } \\
\hline CR & 0 & \multirow{7}{*}{$\begin{array}{c}(0.1-11.9) \\
(38.2-66.7)\end{array}$} \\
\hline PR & $1(2.6)$ & \\
\hline SD & $19(50.0)$ & \\
\hline PD & 5 (13.2) & \\
\hline Unknown & $13(34.2)$ & \\
\hline ORR (CR or PR) & $1(2.6)$ & \\
\hline DCR (CR or PR or SD) & $20(52.6)$ & \\
\hline \multicolumn{3}{|c|}{ Week 12 (by investigator assessment) } \\
\hline CR & 0 & \multirow{7}{*}{$\begin{array}{c}(0.1-11.9) \\
(40.7-69.1)\end{array}$} \\
\hline PR & $1(2.6)$ & \\
\hline SD & $20(52.6)$ & \\
\hline PD & $5(13.2)$ & \\
\hline Unknown & 12 (31.6) & \\
\hline ORR (CR or PR) & $1(2.6)$ & \\
\hline DCR (CR or PR or SD) & $21(55.3)$ & \\
\hline \multicolumn{3}{|c|}{ End of treatment (rederived) } \\
\hline CR & 0 & \multirow{7}{*}{$\begin{array}{c}(0.9-15.7) \\
(38.2-66.7)\end{array}$} \\
\hline PR & $2(5.3)$ & \\
\hline SD & $18(47.4)$ & \\
\hline PD & $5(13.2)$ & \\
\hline Unknown & $13(34.2)$ & \\
\hline ORR (CR or PR) & $2(5.3)$ & \\
\hline $\mathrm{DCR}(\mathrm{CR}$ or $\mathrm{PR}$ or $\mathrm{SD})$ & $20(52.6)$ & \\
\hline \multicolumn{3}{|c|}{ End of treatment (by investigator assessment) } \\
\hline $\mathrm{CR}$ & 0 & \multirow{7}{*}{$\begin{array}{c}(0.9-15.7) \\
(45.9-73.9) \\
\end{array}$} \\
\hline PR & $2(5.3)$ & \\
\hline SD & $21(55.3)$ & \\
\hline PD & 5 (13.2) & \\
\hline Unknown & $10(26.3)$ & \\
\hline ORR (CR or PR) & $2(5.3)$ & \\
\hline $\mathrm{DCR}(\mathrm{CR}$ or $\mathrm{PR}$ or $\mathrm{SD})$ & $23(60.5)$ & \\
\hline \multicolumn{3}{|c|}{ 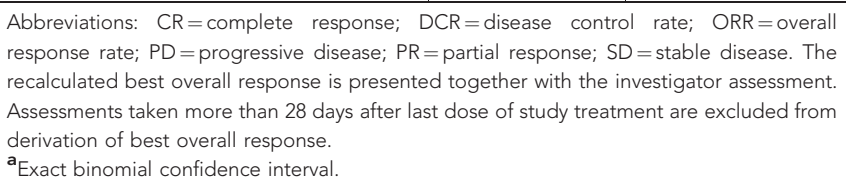 } \\
\hline
\end{tabular}

progression (in 27 patients (71.1\%)) and adverse events (in 8 patients $(21.1 \%))$. Four patients underwent surgical resection of metastases after study entry; of these, three patients had incomplete resection and one patient had macroscopically complete resection. These patients were not censored from the analysis.

At week 12, 20 patients $(52.6 \%, 90 \%$ CI, 38.2-66.7) had the disease controlled (had a PR or SD) based on the rederived best overall response criteria. One patient $(2.6 \%)$ had a PR as the best overall response, and 19 patients (50.0\%) had SD (Table 2). Therefore, the DOVIGIST study met its primary preset efficacy end point (DCR $>20 \%)$. The best overall response was classified as unknown in 13 patients (34.2\%) (8 patients with documented tumour progression after 6 weeks of treatment without confirmation of whether SD lasted $\geqslant 6$ weeks, 1 patient stopped treatment early due to a protocol deviation, and 4 patients exited the study early due to adverse events). Based on the investigator assessment, the DCR at 12 weeks was $55.3 \%$ (21 of $38 ; 90 \%$ CI, 40.7-69.1) (Table 2). The best percentage change from the baseline in the sum of the lesion diameters and the RECIST overall response at the end of study are shown in Figure 1.

By the analysis cutoff date (31 July 2014), 30 PFS events (due to progression) were observed, and the median PFS was 4.6 months (90\% CI, 2.8-7.4 months) (Figure 2). Eight patients $(21.1 \%$ ) discontinued the study due to adverse events and were censored on the date of dovitinib discontinuation. The estimated probability of a patient being progression free at week 12 was $67.5 \%$. The overall survival of the patient population is presented in Figure 3.

The ORR (CR + PR) was $2.6 \%$ ( 1 of $38 ; 90 \%$ CI, $0.1-11.9$ ) and $5.3 \%(n=2 ; 90 \% \mathrm{CI}, 0.9-15.7 \%)$ at week 12 and at the end of study, respectively (based both on rederived and investigator assessment). The median TTP was 4.0 months (95\% CI, 2.7-7.3). The proportion of patients with SD for up to 6 months was $52 \%$ (13 of 25 patients), and the median duration of SD was 167 days (range, 57-490 days). The median OS was not reached, as a majority of the patients were censored because of starting of a new antineoplastic therapy. A sensitivity analysis without censoring at the start of new anticancer therapy showed comparable results.

Exploratory efficacy based on the Choi criteria. The DCR at week 12 and end of study in the full-analysis set were $73.7 \%$ (28 of 38

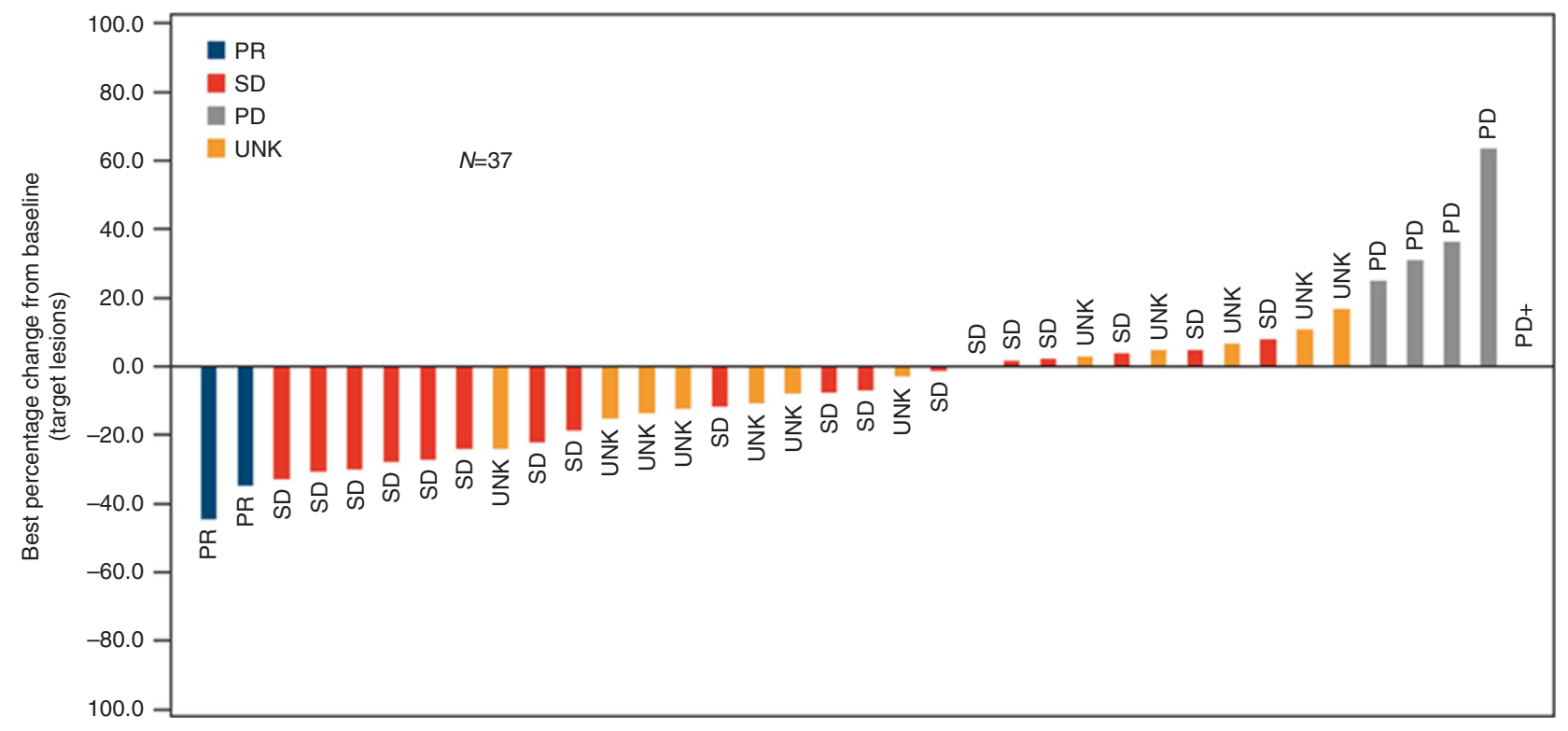

Figure 1. Best percentage change from baseline in sum of lesion diameters and the RECIST overall response at the end of study. 


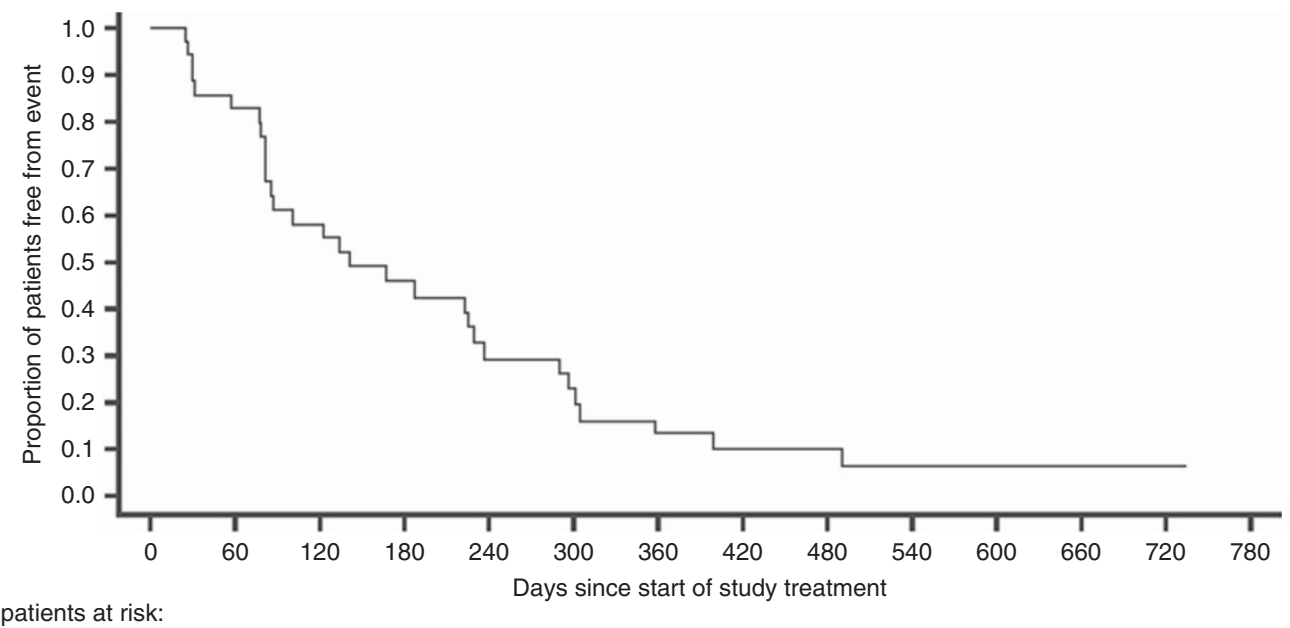

No. of patients at risk:

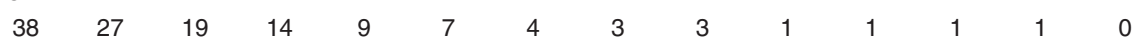

Figure 2. Kaplan-Meier plot of progression-free survival.

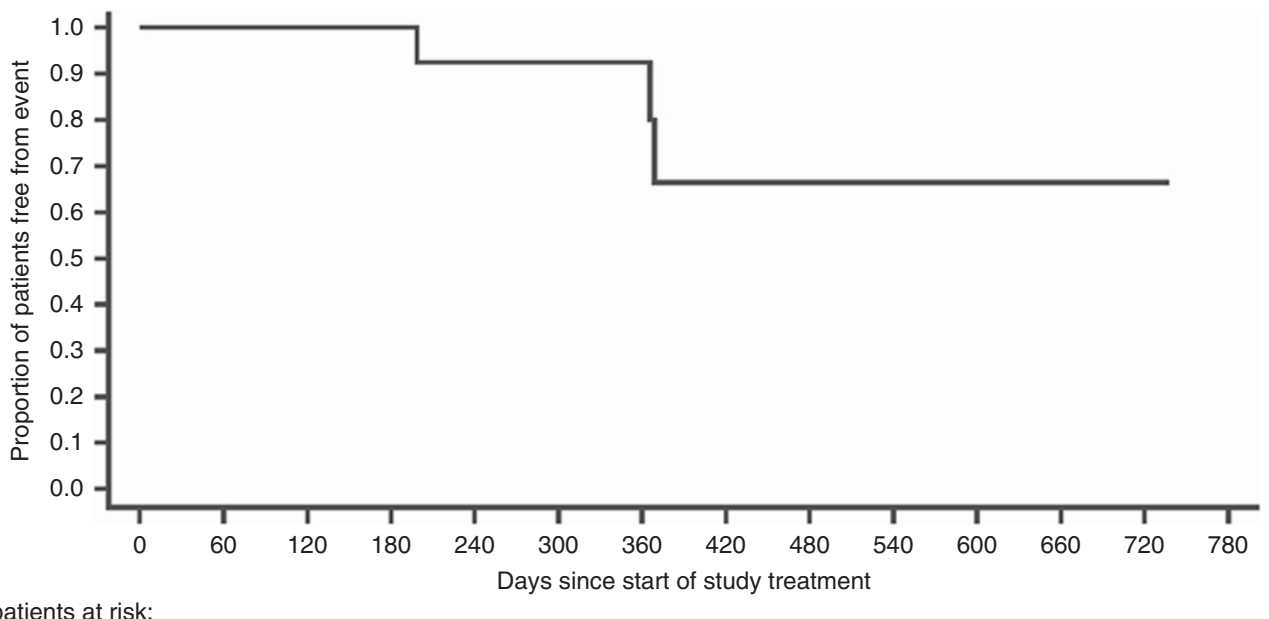

No. of patients at risk:

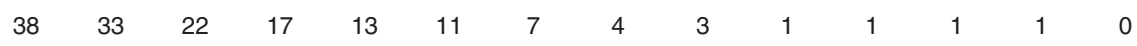

Figure 3. Kaplan-Meier plot of overall survival.

patients; 90\% CI, 59.5-85.0). The overall DCR at week 12 was $44.7 \%$ (17 patients; 90\% CI, 30.9-59.3) and at end of study was 47.4\% (18 patients; 90\% CI, 33.3-61.8).

Response by KIT and PDGFRA mutation. Eight of 14 patients with KIT exon 11 mutation and 1 of 5 patients with KIT exon 9 mutation had SD as the best overall response at week 12. All three patients with PDGFRA mutation had SD.

Safety. The mean daily dose of dovitinib was $437.8 \mathrm{mg}$, and the median relative dose intensity was $96.2 \%$ (range, $49.1-102.2$ ). The median duration of exposure of dovitinib was 14.4 weeks (range, 3.6-105.1 weeks), and 24 patients (61.5\%) had an exposure lasting $>12$ weeks.

All 39 patients used concomitant medications during the treatment with dovitinib. Twenty-three patients (59.0\%) required dose adjustment/interruption and eight patients (20.5\%) discontinued therapy, regardless of the study drug relationship. Dose interruption was required in $26(66.7 \%)$ of 39 patients, with adverse effects being the reason for dose interruption in 18 patients (69.2\%). The reason for dose interruption in the remaining eight patients included a dosing and dispensing error and laboratory test abnormalities.
No significant association in intolerance to imatinib and dovitinib was noted. Of the 8 patients intolerant to imatinib, 4 $(50.0 \%)$ had no dose reduction on dovitinib as compared with 17 (54.8\%) out of the 31 patients who tolerated imatinib $\left(P=0.807, \chi^{2}\right.$ test); the mean number of dovitinib dose reductions per patient were 1.7 (s.d., 2.4) and 1.3 (0.5), respectively.

Thirty-seven of 39 patients $(94.8 \%)$ had an adverse effect reported, and $17(43.6 \%)$ and $8(20.5 \%)$ patients, respectively, had grade 3 or grade 4 adverse effects (Table 3 ). The most frequently observed grade 3 adverse effects were hypertension (7 patients, $17.9 \%$ ), fatigue (5 patients, $12.8 \%$ ), vomiting, hypertriglyceridaemia, and $\gamma$-glutamyl transferase increase (4 patients each, 10.3\%). Most of these adverse effects were suspected to be dovitinib related. Almost all patients (36 patients, 92.3\%) experienced $\geqslant 1$ adverse effects suspected to be study drug related, a majority of which were grade 3 or 4 (23 patients, 59\%). Grade 3 adverse effects occurred in 19 patients $(48.7 \%)$; the most frequent ones (occurred in $\geqslant 3 \%$ of the patients) were fatigue (5 patients, $12.8 \%$ ), hypertension (4 patients, $10.3 \%$ ), diarrhoea, $\gamma$-glutamyl transferase increase, vomiting, hypertriglyceridaemia (3 patients each, 7.7\%), nausea, anaemia, neutropenia, mucosal inflammation, and asthenia (2 patients each, 5.1\%). Grade 4 adverse effects suspected to be related to dovitinib were observed in four patients $(10.3 \%)$. The 
Table 3. The most frequently recorded adverse events (occurred in $>30 \%$ of the patients)

\begin{tabular}{|c|c|c|c|c|}
\hline \multirow[b]{2}{*}{ Adverse events } & \multicolumn{4}{|c|}{ Dovitinib $(N=39)$} \\
\hline & $\begin{array}{c}\text { Grade } \\
1, n(\%)\end{array}$ & $\begin{array}{c}\text { Grade } \\
2, n(\%)\end{array}$ & $\begin{array}{l}\text { Grade } \\
3, n(\%)\end{array}$ & $\begin{array}{c}\text { Grade } \\
4, n \\
(\%)\end{array}$ \\
\hline Patients with any $\mathrm{AE}$ & $2(5.1)$ & $10(25.6)$ & $17(43.6)$ & $\begin{array}{c}8 \\
(20.5)\end{array}$ \\
\hline \multicolumn{5}{|l|}{ Adverse effect } \\
\hline Diarrhoea & $14(35.9)$ & $11(28.2)$ & $3(7.7)$ & 0 \\
\hline Vomiting & $10(25.6)$ & 7 (17.9) & $4(10.3)$ & 0 \\
\hline Nausea & $6(15.4)$ & $9(23.1)$ & $2(5.1)$ & 0 \\
\hline Asthenia & $5(12.8)$ & $8(20.5)$ & $1(2.6)$ & $1(2.6)$ \\
\hline Decreased appetite & $6(15.4)$ & $7(17.9)$ & $2(5.1)$ & 0 \\
\hline Fatigue & $3(7.7)$ & $6(15.4)$ & $5(12.8)$ & 0 \\
\hline $\begin{array}{l}\gamma \text {-Glutamyl transferase } \\
\text { increase }\end{array}$ & $4(10.3)$ & $5(12.8)$ & $4(10.3)$ & $1(2.6)$ \\
\hline $\begin{array}{l}\text { Blood alkaline } \\
\text { phosphatase increase }\end{array}$ & $9(23.1)$ & $2(5.1)$ & $2(5.1)$ & 0 \\
\hline Hypertension & 0 & $6(15.4)$ & $7(17.9)$ & 0 \\
\hline Hypertriglyceridaemia & $2(5.1)$ & $7(17.9)$ & $4(10.3)$ & 0 \\
\hline Weight decreased & $8(20.5)$ & $3(7.7)$ & $1(2.6)$ & 0 \\
\hline
\end{tabular}

Abbreviation: $A E=$ adverse events. Only adverse effects that occurred during dovitinib treatment or within 28 days from the last day of dovitinib administration are reported.

grade 4 adverse effects recorded were leukopaenia, pancytopenia, cardiac arrest, cholestasis, and $\gamma$-glutamyl transaminase increase (1 patient each, $2.6 \%$ ).

Serious adverse effects suspected to be study treatment related were reported in 10 patients $(25.6 \%)$; these were fatigue ( 2 patients, $5.1 \%)$, vomiting (2 patients, 5.1\%), anaemia, leukopaenia, pancytopenia, cardiac arrest, tachycardia, diarrhoea, nausea, cholestasis, tracheobronchitis, decreased weight, decreased appetite, peripheral neuropathy, pulmonary embolism, toxic skin eruption, and aortic thrombosis (1 patient each, 2.6\%). One patient died during the study due to a cardiac arrest, which was suspected to be related to dovitinib.

\section{DISCUSSION}

In this phase 2 study, we investigated the safety and efficacy of dovitinib administered at $500 \mathrm{mg} \mathrm{day}^{-1}, 5$ days on/2 days off in patients with imatinib refractory/intolerant GIST, but who had not been treated with sunitinib or regorafenib. This study met its prespecified efficacy objective demonstrating a DCR $(\mathrm{CR}+\mathrm{PR}+$ SD) of $52.6 \%$ at 12 weeks. The median PFS was 4.6 months, and the median OS was not reached.

The identification of driver mutations in genes encoding receptor tyrosine kinases and development of potent inhibitors of these kinases revolutionised treatment for GIST. Imatinib was approved in 2002 for the treatment of patients with metastatic and/ or unresectable GIST and is the standard therapeutic option in the first-line setting (Dagher et al, 2002). Tyrosine kinase inhibitor therapies have greatly improved survival of patients with advanced GIST. According to one estimate, the median survival of patients with unresectable or metastatic GIST increased after the introduction of imatinib from 12 to 33 months (Artinyan et al, 2008). A more recent study suggests that the median survival of patients with advanced GIST treated with TKIs increased from 1 to at least 5 years (Casali, 2014). However, GIST patients frequently develop resistance to imatinib and have disease progression mainly due to secondary KIT mutations (Antonescu et al, 2005; Heinrich et al, 2006; Wardelmann et al, 2006; Gramza et al, 2009), and therefore, there is still an unmet medical need. Most of the acquired mutations occur in KIT exon 13, exon 14 (encode the adenosine triphosphate/drug-binding pocket), or exon 17 that encodes the kinase activation loop (Wardelmann et al, 2006; Gramza et al, 2009). The median time to progression on first-line imatinib is about 3 years, although some patients remain progression free for longer than 10 years.

Sunitinib, an approved second-line treatment for imatinib refractory/intolerant GIST (Yoo et al, 2013), has potent activity on GISTs with KIT exon 13 and 14 mutations that confer imatinib resistance, but relatively little activity against KIT exon 17 and exon 18 mutations (Heinrich et al, 2008; Nishida et al, 2009; Heinrich et al 2012). In a phase 2 study on patients $(n=97)$ intolerant/ progressing on imatinib, sunitinib demonstrated a clinical benefit rate (PR or SD > 6 months) of $58 \%$ and $34 \%$ for patients with KIT exon 9 or exon 11 mutations, respectively. The median PFS (19.4 vs 5.1 months) and OS (26.9 vs 12.3 months) were better for patients with primary KIT exon 9 mutations than patients with exon 11 mutations (Heinrich et al, 2008). In addition, PFS and OS were longer in patients with secondary KIT exon 13 and 14 mutations compared with those with mutations in exons 17 and 18 (Heinrich et al, 2008). In the present study, 8 (57\%) of 14 patients with KIT exon 11 primary tumour mutation had the disease controlled at least for 6 weeks, but the small numbers preclude from making firm conclusions about the efficacy of dovitinib in different mutational subsets.

Dovitinib had been evaluated earlier in the treatment of advanced GIST in the third-line setting (Kang et al, 2013). In that study with 30 patients whose GIST had progressed at least on imatinib and sunitinib, a median PFS of 3.6 months and median OS of 9.7 months were achieved, and the DCR was $13 \%$ at 24 weeks after study entry. One patient achieved PR and other 21 patients achieved SD, whereas 6 patients had PD (Kang et al, 2013).

Besides sunitinib and dovitinib, a few other TKIs have been investigated as second-line therapy for imatinib-resistant GIST. These include vatalanib (Joensuu et al, 2011), motesanib (Benjamin et al, 2011), and masitinib (Adenis et al, 2014). Vatalanib, an inhibitor of KIT, PDGFRA, and the VEGFRs, was found well tolerated. Two of 26 patients (8\%) treated with prior imatinib only for advanced GIST achieved PR and further 12 patients (66\%) had stable disease lasting for at least 6 months, and the median time to progression was 5.8 months (Joensuu et al, 2011). Of the 102 patients with imatinib-resistant GIST and treated with motesanib, another inhibitor of KIT, PDGFRA, and the VEGFRs, $3(3 \%)$ patients achieved PR, 60 (59\%) had SD for $\geqslant 8$ weeks, 14 (14\%) had durable SD lasting for a minimum of 24 weeks, and the median progression-free survival was 3.7 months (Benjamin et al, 2011). Masitinib, an inhibitor of KIT, PDGFR, and the fibroblast growth factor receptor-3, was compared with sunitinib in a small randomised trial in the second-line setting in patients whose GIST had progressed on imatinib. The median progression-free survival was 3.7 months in the masitinib arm, which was similar to that of patients treated with sunitinib. Masitinib was, however, better tolerated than sunitinib (Adenis et al, 2014). Taken together, the response rate and the median time to progression observed in the present study with dovitinib might not differ substantially from those obtained with these other TKIs, including sunitinib, in the second-line setting, although efficacy comparisons between different studies are notoriously difficult and might even be misleading.

The side-effect profile of dovitinib was comparable with TKIs that inhibit the VEGFRs besides KIT and PDGFRA, with hypertension frequently detected. One patient died from cardiac arrhythmia, which may have been due to dovitinib-related hypertension or other cardiac toxicity. Dovitinib was associated with relatively frequent gastrointestinal tract toxicity including nausea, vomiting, and diarrhoea. Dovitinib treatment was discontinued owing to adverse events in $8(21 \%)$ patients, and 
the dosing was either reduced or interrupted in 22 (58\%) patients owing to toxicity. Overall, these findings suggest that the tolerability of dovitinib might be roughly similar to other TKIs that inhibit multiple kinases including KIT, PDGFRA, and the VEGFRs.

The study has limitations. The response to dovitinib was unknown in a considerable number of patients (13 patients, $34 \%$ ). This was due to interpreting responses and SD conservatively. Patients with a best overall response classified as 'unknown' were not regarded as responders, but were included in the denominator for the calculation of the DCR. Patients not qualifying for confirmed CR or PR and who did not have SD after more than 6 weeks or early progression within the first 6 weeks after study entry were considered to have 'unknown' response. We also calculated the proportion of patients who had the disease controlled in two ways, as SD on investigator assessment could not be confirmed in two cases. This did not, however, substantially alter the study primary outcome (Table 2). Finally, we lacked mutation analysis results of KIT and PDGFRA in $34 \%$ of the patients.

In sum, dovitinib was associated with a clinically meaningful benefit as second-line treatment of patients with imatinibrefractory GIST or who did not tolerate imatinib, and the primary efficacy end point of the study was met. Dovitinib safety profile was generally acceptable, but one patient was judged to have died from dovitinib-related cardiac arrhythmia. Many of the patients with primary tumour KIT exon 11 mutation benefitted from dovitinib, and further studies might identify a specific subgroup of patients who benefit from dovitinib therapy in the second-line setting. While sunitinib remains the standard second-line treatment, the results of the present study suggest a need for further investigation of dovitinib in the treatment of advanced GIST.

\section{ACKNOWLEDGEMENTS}

We thank the patients who took part in this trial, the investigators, study nurses, and clinical research associates from the individual trial centres who supported this trial. We also thank Amirtha Ganesh, PhD (Novartis Healthcare Pvt Ltd), for providing medical editorial assistance with this manuscript. This work was financially supported by Novartis Oncology.

\section{CONFLICT OF INTEREST}

HJ receives honoraria for consultancy with Blueprint Medicines, Ariad Pharmaceuticals, and Orion Pharma. J-YB reports grants and personal fees from Novartis, grants and personal fees from Bayer, grants and personal fees from Roche, and grants and personal fees from Pfizer, outside the submitted work. AC has nothing to disclose. JM-B serves on the advisory board of Novartis, outside of the submitted work. EF has nothing to disclose. GG reports personal fees from Bayer, personal fees from Novartis, and personal fees from Pfizer, outside the submitted work. XGDM reports advisory role and receiving funding for research from Pfizer and Bayer. AA reports personal fees from Novartis, outside the submitted work. CV reports personal fees from Novartis, personal fees from Bayer, personal fees from Lilly, and personal fees from Pfizer, outside the submitted work. ALP has nothing to disclose. OB reports grants from Novartis, during the conduct of the study; personal fees from Novartis, personal fees from Roche, personal fees from Merck, personal fees from Lilly, and personal fees from Hospira, outside the submitted work. AI has nothing to disclose. SB reports grants and other from Novartis, grants from Blueprint Medicine, grants from Ariad, other from Bayer, other from Pfizer, other from Lilly, during the conduct of the study. $\mathrm{CB}$ reports grants from Novartis, outside the submitted work. CW, SC, $\mathrm{MC}$, and RC are Novartis employees. ALC reports personal fees from Pfizer, personal fees from Pharmamar, personal fees from Amgen, personal fees from Lilly, and personal fees from NovartisGSK, outside the submitted work.

\section{REFERENCES}

Adenis A, Blay JY, Bui-Nguyen B, Bouche O, Bertucci F, Isambert N, Bompas E, Chaigneau L, Domont J, Ray-Coquard I, Blésius A, Van Tine BA, Bulusu VR, Dubreuil P, Mansfield CD, Acin Y, Moussy A, Hermine O, Le Cesne A (2014) Masitinib in advanced gastrointestinal stromal tumour (GIST) after failure of imatinib: a randomized controlled open-label study. Ann Oncol 25: 1762-1769.

Agaimy A, Wunsch PH, Hofstaedter F, Blaszyk H, Rummele P, Gaumann A, Dietmaier W, Hartmann A (2007) Minute gastric sclerosing stromal tumors (GIST tumorlets) are common in adults and frequently show c-KIT mutations. Am J Surg Pathol 31: 113-120.

Antonescu CR, Besmer P, Guo T, Arkun K, Hom G, Koryotowski B, Leversha MA, Jeffrey PD, Desantis D, Singer S, Brennan MF, Maki RG, DeMatteo RP (2005) Acquired resistance to imatinib in gastrointestinal stromal tumor occurs through secondary gene mutation. Clin Cancer Res 11: 4182-4190.

Artinyan A, Kim J, Soriano P, Chow W, Bhatia S, Ellenhorn JD (2008) Metastatic gastrointestinal stromal tumors in the era of imatinib: improved survival and elimination of socioeconomic survival disparities. Cancer Epidemiol Biomarkers Prev 17: 2194-2201.

Bauer S, Joensuu H (2015) Emerging agents for the treatment of advanced, imatinib resistant gastrointestinal stromal tumors: current status and future directions. Drugs 75: 1323-1324.

Benjamin RS, Schöffski P, Hartmann JT, Van Oosterom A, Bui BN, Duyster J, Schuetze S, Blay JY, Reichardt P, Rosen LS, Skubitz K, McCoy S, Sun YN, Stepan DE, Baker L (2011) Efficacy and safety of motesanib, an oral inhibitor of VEGF,PDGF, and Kit receptors, in patients with imatinib-resistant gastrointestinal stromal tumors. Cancer Chemother Pharmacol 68: 69-77.

Casali PG (2014) Success and limitation of targeted cancer therapy in gastrointestinal stromal tumors. Prog Tumor Res 41: 51-61.

Cauchi C, Somaiah N, Engstrom PF, Litwin S, Lopez M, Lee J, Davey M, Bove B, von Mehren M (2012) Evaluation of nilotinib in advanced GIST previously treated with imatinib and sunitinib. Cancer Chemother Pharmacol 69: 977-982.

Corless CL, Barnett CM, Heinrich MC (2011) Gastrointestinal stromal tumours: origin and molecular oncology. Nat Rev Cancer 11: 865-878.

Dagher R, Cohen M, Williams G, Rothmann M, Gobburu J, Robbie G, Rahman A, Chen G, Staten A, Griebel D, Pazdur R (2002) Approval summary: imatinib mesylate in the treatment of metastatic and/or unrespectable malignant gastrointestinal stromal tumors. Clin Cancer Res 8: 3034-3048.

Debiec-Rychter M, Sciot R, Le Cesne A, Schlemmer M, Hohenberger P, van Oosterom AT, Blay JY, Leyvraz S, Stul M, Casali PG, Zalcberg J, Verweij J, Van Glabbeke M, Hagemeijer A, Judson I. EORTC Soft Tissue and Bone Sarcoma Group; Italian Sarcoma Group; Australasian GastroIntestinal Trials Group (2006) KIT mutations and dose selection for imatinib in patients with advanced gastrointestinal stromal tumours. Eur $J$ Cancer 42: 1093-1103.

Demetri G, Reichardt P, Kang Y, Blay J-Y, Rutkowski P, Gelderbloom H, Hohenberger P, Leahy M, von Mehren M, Joensuu H, Badalamenti G, Blackstein M, Le Cesne A, Schöffski P, Maki RG, Bauer S, Nguyen BB, Xu J, Nishida T, Chung J, Kappeler C, Kuss I, Laurent D, Casali PG. GRID Study Investigators (2013) Efficacy and safety of regorafenib for advanced gastrointestinal stromal tumors after failure of imatinib and sunitinib (GRID): an international multicentre, randomized placebo-controlled, phase 3 trial. Lancet 381: 295-302.

Demetri GD, van Oosterom AT, Garrett CR, Blackstein ME, Shah MH, Verweij J, McArthur G, Judson IR, Heinrich MC, Morgan JA, Desai J, Fletcher CD, George S, Bello CL, Huang X, Baum CM, Casali PG (2006) Efficacy and safety of sunitinib in patients with advanced gastrointestinal stromal tumor after failure of imatinib: a randomised controlled trial. Lancet 368: 1329-1338. 
Ganjoo KN, Villalobos VM, Kamaya A, Fisher GA, Butrynski JE, Morgan JA, Morgan JA, Wagner AJ, D'Adamo D, McMillan A, Demetri GD, George S (2014) A multicenter phase II study of pazopanib in patients with advanced gastrointestinal stromal tumors (GIST) following failure of at least imatinib and sunitinib. Ann Oncol 25: 236-240.

Gramza AW, Corless CL, Heinrich MC (2009) Resistance to tyrosine kinase inhibitors in gastrointestinal stromal tumors. Clin Cancer Res 15: 7510-7518.

Heinrich MC, Corless CL, Blanke CD, Demetri GD, Joensuu H, Roberts PJ, Eisenberg BL, von Mehren M, Fletcher CD, Sandau K, McDougall K, Ou WB, Chen CJ, Fletcher JA (2006) Molecular correlates of imatinib resistance in gastrointestinal stromal tumors. J Clin Oncol 24: 4764-4774.

Heinrich MC, Maki RG, Corless CL, Antonescu CR, Harlow A, Griffith D, Town A, McKinley A, Ou WB, Fletcher JA, Fletcher CD, Huang X, Cohen DP, Baum CM, Demetri GD (2008) Primary and secondary kinase genotypes correlate with the biological and clinical activity of sunitinib in imatinib-resistant gastrointestinal stromal tumor. J Clin Oncol 26: 5352-5359.

Heinrich MC, Marino-Enriquez A, Presnell A, Donsky RS, Griffith DJ, McKinley A, Patterson J, Taguchi T, Liang CW, Fletcher JA (2012) Sorafenib inhibits many kinase mutations associated with drug-resistant gastrointestinal stromal tumors. Mol Cancer Ther 11: 1770-1780.

Joensuu H, De Braud F, Grignagni G, De Pas T, Spitalieri G, Coco P, Spreafico C, Boselli S, Toffalorio F, Bono P, Jalava T, Kappeler C, Aglietta M, Laurent D, Casali PG (2011) Vatalanib for metastatic gastrointestinal stromal tumour (GIST) resistant to imatinib: final results of a phase II study. Br J Cancer 104: 1686-1690.

Joensuu H, Hohenberger P, Corless CL (2013) Gastrointestinal stromal tumour. Lancet 382: 973-983.

Kang YK, Yoo C, Ryoo BY, Lee JJ, Tan E, Park I, Park JH, Choi YJ, Jo J, Ryu JS, Ryu MH (2013) Phase II study of dovitinib in patients with metastatic and/or unresectable gastrointestinal stromal tumors after failure of imatinib and sunitinib. Br J Cancer 109: 2309-2315.

Miettinen M, Lasota J (2006) Gastrointestinal stromal tumors: review on morphology, molecular pathology, prognosis, and differential diagnosis. Arch Pathol Lab Med 130: 1466-1478.

Montemurro M, Gelderblom H, Bitz U, Schutte J, Blay JY, Joensuu H, Trent J, Bauer S, Rutkowski P, Duffaud F, Pink D (2013) Sorafenib as third- or fourth-line treatment of advanced gastrointestinal stromal tumour and pretreatment including both imatinib and sunitinib, and nilotinib: a retrospective analysis. Eur J Cancer 49: 1027-1031.

Muenst S, Thies S, Went P, Tornillo L, Bihl MP, Dirnhofer S (2011) Frequency, phenotype, and genotype of minute gastrointestinal stromal tumors in the stomach: an autopsy study. Hum Pathol 42: 18491854.

Nishida T, Kawai N, Yamaguchi S, Nishida Y (2013) Submucosal tumors: comprehensive guide for the diagnosis and therapy of gastrointestinal submucosal tumors. Dig Endosc 25: 479-489.
Nishida T, Takahashi T, Nishitani A, Doi T, Shirao K, Komatsu Y, Nakajima K, Hirota S. Japanese Study Group on GIST (2009) Sunitinib-resistant gastrointestinal stromal tumors harbor cismutations in the activation loop of the KIT gene. Int J Clin Oncol 14: 143-149.

Pilotte AP (2015) Current management of patients with gastrointestinal stromal tumor receiving the multitargeted tyrosine kinase inhibitor sunitinib. Curr Med Res Opin 31: 1363-1376.

Porta C, Giglione P, Liguigli W, Paglino C (2015) Dovitinib (CHIR258, TKI258): structure, development and preclinical and clinical activity. Fut Oncol 11: 39-50.

Sarker D, Molife R, Evans TR, Hardie M, Marriott C, Butzberger-Zimmerli P, Morrison R, Fox JA, Heise C, Louie S, Aziz N, Garzon F, Michelson G, Judson IR, Jadayel D, Braendle E, de Bono JS (2008) A phase I pharmacokinetic and pharmacodynamic study of TKI258, an oral, multitargeted receptor tyrosine kinase inhibitor in patients with advanced solid tumors. Clin Cancer Res 14: 2075-2081.

Tran T, Davila JA, El-Serag HB (2005) The epidemiology of malignant Gastrointestinal Stromal Tumors: an analysis of 1458 cases from 1992 to 2000. Am J Gastroenterol 100: 162-168.

Trudel S, Li ZH, Wei E, Wiesmann M, Chang H, Chen C, Reece D, Heise C, Stewart AK (2005) CHIR-258, a novel multitargeted tyrosine kinase inhibitor for the potential treatment of $\mathrm{t}(4 ; 14)$ multiple myeloma. Blood 105: 2941-2948.

Van Glabbeke M, Verweij J, Casali PG, Le Cesne A, Hohenberger P, Ray-Coquard I, Schlemmer M, van Oosterom AT, Goldstein D, Sciot R, Hogendoorn PC, Brown M, Bertulli R, Judson IR (2005) Initial and late resistance to imatinib in advanced gastrointestinal stromal tumors are predicted by different prognostic factors: a European Organisation for Research and Treatment of Cancer-Italian Sarcoma Group-Australasian Gastrointestinal Trials Group study. J Clin Oncol 23: 5795-5804.

Wardelmann E, Merkelbach-Bruse S, Pauls K, Thomas N, Schildhaus HU, Heinicke T, Speidel N, Pietsch T, Buettner R, Pink D, Reichardt P, Hohenberger P (2006) Polyclonal evolution of multiple secondary KIT mutations in gastrointestinal stromal tumors under treatment with imatinib mesylate. Clin Cancer Res 12: 1743-1749.

Yoo C, Ryu MH, Tyoo BY, Beck MY, Kang YK (2013) Efficacy, safety, and pharmacokinetics of imatinib dose escalation to $800 \mathrm{mg}$ /day in patients with advanced gastrointestinal stromal tumors. Invest New Drugs 31: 1367-1374.

(c) (1) (2) (2) This work is licensed under the Creative Commons (c) 1 BY NG SA Attribution-Non-Commercial-Share Alike 4.0 International License. To view a copy of this license, visit http:// creativecommons.org/licenses/by-nc-sa/4.0/

(C) The Author(s) named above 2017 